\title{
PONDERAÇÃO DE DIREITOS E PROPORCIONALIDADE DAS DECISÕES JUDICIAIS
}

\author{
Josué Mastrodi
}

ON BALANCING RIGHTS AND PROPORTIONALITY OF JUDICIAL DECISIONS

\section{RESUMO}

PESQUISA SOBRE A PREVALÊNCIA DE INTERESSES E VALORES DOS GRUPOS SOCIAIS MAIS ELEVADOS CONTRA INTERESSES E VALORES DOS GRUPOS SOCIAIS SUBORDINADOS MESMO EM DECISÕES JUDICIAIS DE CONFLITOS APARENTEMENTE INDIVIDUAIS, QUE ENVOLVEM APENAS AUTOR E RÉU. OS DIREITOS INDIVIDUAIS, SOBRE OS QUAIS O ESTADO MODERNO FOI ESTRUTURADO, TENDEM A PREVALECER SOBRE OS DIREITOS SOCIAIS. ESSA PREVALÊNCIA É DETERMINANTE MESMO NO ÂMBITO DA TEORIA DOS DIREITOS FUNDAMENTAIS DE ROBERT ALEXY, EM QUE SE AFIRMA IGUAL IMPORTÂNCIA A DIREITOS INDIVIDUAIS OU SOCIAIS E QUE, PELA PROPORCIONALIDADE, HAVERIA CHANCE DE DIREITOS SOCIAIS PREVALECEREM. É ATÉ POSSÍVEL AFIRMAR QUE CADA COLISÃO DE DIREITOS SERÁ DECIDIDA DE MODO PROPORCIONAL E DE FORMA DIFERENTE, MAS A PROPORCIONALIDADE NÃO CONFERE RACIONALIDADE AO CRITÉRIO NECESSÁRIO PARA FUNDAMENTAR A DECISÃO. A DECISÃO PROPORCIONAL TEM MAIS RELAÇÃO COM O CRITÉRIO ESCOLHIDO QUE COM OS DIREITOS EM CONFLITO.

\section{PALAVRAS-CHAVE}

Teoria Geral do Direito; Direitos Fundamentais; Ponderação de direitos; Proporcionalidade; Robert Alexy.

\section{ABSTRACT}

RESEARCH ON THE PREVALENCE OF INTERESTS AND VALUES OF HIGHER SOCIAL GROUPS OVER INTERESTS AND VALUES OF LOWER SOCIAL GROUPS EVEN IN JUDICIAL DECISIONS BETWEEN TWO INDIVIDUALS ONLY, AUTHOR AND DEFENDANT. INDIVIDUAL RIGHTS, BY WHICH MODERN STATE HAS BEEN STRUCTURED, TENDS TO PREVAIL. THIS PREVALENCE IS AS WELL DETERMINANT IN ROBERT ALEXY'S THEORY OF FUNDAMENTAL RIGHTS, BY WHICH IS GIVEN SAME IMPORTANCE EITHER TO INDIVIDUAL OUR SOCIAL RIGHTS AND, DUE TO PROPORTIONAL BALANCING, THERE IS CHANCE SOCIAL RIGHTS TO WIN. IT IS POSSIBLE TO ASSERT THAT EACH COLLISION OF RIGHTS WILL BE DECIDED DIFFERENTLY, BUT PROPORTIONALITY DOES NOT ATTRIBUTE RATIONALITY TO THE CRITERION NEEDED TO GIVE RATIO DECIDENDUM TO THE DECISION. THE PROPORTIONAL DECISION IS MORE RELATED TO THE CHOSEN CRITERION THAN TO THE RIGHTS IN CONFLICT.

\section{KEYWORDS}

GENERAL THEORY OF LAW; THEORY OF FUNDAMENTAL RIGHTS; BALANCING OF RIGHTS; PROPORTIONALITY; ROBERT ALEXY.

\section{INTRODUÇÃO}

Este artigo foi concebido no final do ano de 2012 no âmbito de um plano de pesquisa que visava basicamente a dois objetivos: em termos teóricos, por meio de análise descritiva feita a partir de revisão bibliográfica, identificar o caráter fictício do princípio ou postulado da proporcionalidade, em especial o desenvolvido nos termos da impressionante teoria dos direitos fundamentais de Robert Alexy; e, em termos empíricos, 
a partir de análise de acórdãos do Supremo Tribunal Federal (STF), identificar as formas pelas quais o STF soluciona conflitos que envolvem colisão de direitos fundamentais, em especial se tais formas guardam relação com a proporcionalidade de Alexy (tanto no procedimento de identificar os testes de adequação, necessidade e proporcionalidade em sentido estrito) quanto na substância (se há ponderação entre direitos, valores e interesses, sem hierarquia necessária entre eles). Pela quantidade de acórdãos encontrada na base de dados do STF, ${ }^{1}$ este segundo objetivo não se mostrou exequível no curto prazo e, portanto, seus resultados somente serão apresentados em trabalho posterior.

Nesse sentido, este artigo tem por finalidade exclusiva apresentar os resultados obtidos no âmbito da pesquisa teórica, em que se identificou a natureza fictícia do instrumento de solução de conflitos por excelência da teoria dos direitos fundamentais - o princípio ou postulado da proporcionalidade - a partir de uma crítica imanente aos estatutos dessa mesma teoria. Constatou-se que a proporcionalidade não possui elementos inovadores em relação a outros meios de solução de conflitos, tampouco hábeis a resolução de conflitos reais. Em que essa forma de solução de conflitos supera as já desenvolvidas pelas teorias tradicionais? Parece-me que a resposta não está na proporcionalidade, mas na estrutura da teoria proposta por Alexy que, ao contrário das demais teorias normativas, não predetermina normas a partir de uma tábua de valores, compreendendo o pluralismo político da atualidade de modo muito mais abrangente (i.e., todos os interesses, valores e direitos, desde que previstos em norma constitucional, devem ser protegidos na maior medida possível).

Não obstante, a teoria de Alexy, em especial por ser de natureza funcionalista, também precisaria superar as demais teorias jurídicas na sua aplicação. Como a aplicação depende ineludivelmente da proporcionalidade, esta precisa, a meu ver, de certas precisões em sua definição e em sua utilização. O intérprete tem total liberdade para escolher o critério pelo qual fará a comparação entre os direitos em colisão e a ponderação pela qual decidirá por um direito ou pelo outro; com isso, a proporcionalidade não é a relação otimizada de adequação e necessidade entre os direitos em jogo, mas a relação entre o critério adotado para se decidir e a decisão efetivamente tomada, correndo-se o risco de esta decisão não guardar relação alguma com os direitos em conflito, já que o critério escolhido pode servir mais para justificar a decisão tomada que para mensurar os direitos em jogo e estabelecer quanto de cada um deverá ser protegido em cada caso concreto.

A proporcionalidade foi inicialmente desenvolvida no âmbito do Tribunal Administrativo Prussiano entre os anos de 1882 a 1914, como forma de controle dos atos da Administração Pública (COHEN-ELIYA; PORAT, 2010), justamente pela verificação da existência de proporção entre o motivo (critério de ação) e a finalidade pública a ser atingida (realização efetiva da decisão tomada). Não havia, em sua origem, discussão entre direitos individuais ou sociais em conflito, sua função era 
identificar em que medida seria lícito à Administração Pública interferir na esfera privada dos administrados. Em Alexy, a proporcionalidade é ampliada e serve como base para comparação e aplicação ponderada de direitos e interesses em conflito; porém, ao menos segundo o ponto de vista apresentado neste artigo, a proporcionalidade da Teoria dos Direitos Fundamentais continua a relacionar a decisão tomada com o critério utilizado para se decidir, embora afirme tratar-se de efetiva ponderação entre os direitos em colisão.

Estruturo este artigo do seguinte modo: no item 1, a seguir, trato da transformação dos conflitos reais em conflitos jurídicos, da forma como as teorias jurídicas buscam resolver o conflito real pela solução dada ao conflito jurídico e da forma como isso se dá no âmbito da teoria dos direitos fundamentais. No item 2, trato dos caracteres que conferem à proporcionalidade natureza de um postulado, e não a de um princípio, isto é, trata-se de um pressuposto teórico, fundamento de toda a teoria de Robert Alexy, sem correspondência no mundo real ou mesmo no sistema normativo. Trata-se de uma ferramenta teórica imprescindível para a ponderação de direitos, mas essa ponderação se dá por força do elemento ficcional da teoria (o postulado da proporcionalidade) e não por um dado da realidade. Ao final, teço considerações sobre as formas de a proporcionalidade, ainda que entendida como ficção, relacionar a decisão com os direitos em conflito e estes com a realidade fática.

Não pretendo analisar exaustivamente a teoria de Robert Alexy, em especial por já ser amplamente divulgada e conhecida, por já possuir comentadores e críticos da mais alta qualidade (ALEXY, 2001 e 2002; KLATT; EISTER, 2012; KUMM, 2004; MÖLLER, 2007 e 2012; SILVA, 2011; TSAKYRAKIS, 2009), e também porque o espaço deste artigo não permitiria tal intento. No entanto, algumas de suas características serão delineadas na medida em que isso se apresentar necessário para o desenvolvimento deste trabalho.

\section{LUTAS SOCIAIS, CRISTALIZAÇÃO DAS RELAÇÕES DE PODER NA FORMA DE DiReitos. A TRADUÇÃO DAS LUTAS NA FORMA DE CONFLITOS JUDICIAIS}

Os conflitos reais podem ser decididos por meio de força física ou poder econômico. Esses conflitos envolvem a luta por bens ou posições sociais, disputados pelo valor ou interesse que eles representam. Qualquer bem ou posição possui um valor determinado pelas vantagens que ele proporciona a seu detentor (vantagens estas que não são apenas de ordem econômica, a dimensão que acaba por permitir a atribuição de valor de troca ao bem ou posição).

No âmbito da ciência do direito, tanto os autores (pesquisadores) quanto os atores jurisdicionais (em especial, os juízes) partem do pressuposto ${ }^{2}$ de que um conflito real deve ser entendido, na arena do discurso, não mais como um conflito, mas como uma discussão que envolve valores e interesses contrapostos. Além disso, a discussão 
é transformada em uma colisão de princípios normativos, que é a forma como, dentro do direito, se compreende a discussão para o fim de resolvê-la por meio de uma decisão. ${ }^{3}$ Dentro do Estado de Direito, a disputa deve ser decidida não mais pela força das partes, mas por uma decisão de autoridade. Num conflito a ser decidido pelo Estado, o poder econômico ou físico dos litigantes não deve ser considerado em hipótese alguma. O fator determinante da resolução do conflito é a identificação de que uma das partes possui um título que justifique vencer a disputa. Esse título são as posições jurídicas denominadas direitos subjetivos.

Direitos são a cristalização, em normas jurídicas, de valores ou interesses considerados importantes pela sociedade que os positivou. A partir de um determinado contexto histórico, certas condutas são valoradas como boas ou ruins conforme a possibilidade de tais condutas permitirem a satisfação de interesses ou necessidades. Como não é possível que dois interesses sejam satisfeitos ao mesmo tempo com o mesmo recurso, há disputa no sentido de se atribuir valor positivo às condutas que levam à satisfação dos interesses contrapostos. Isso não é simplesmente negociado num contrato social em que todos são livres e iguais. Há relações sociais concretas em que pessoas e grupos, por causa de sua posição social concretamente predominante, são capazes de fazer essa predominância prevalecer, também, no estabelecimento das normas jurídicas gerais e abstratas que, ao serem positivadas, são aplicáveis a todos os membros da sociedade, de modo que a estrutura de desigualdade social é transformada em um ordenamento que se apresenta como se fosse justo ou bom de modo universal para todos os membros daquela sociedade. E a ciência do direito acaba por tratar desta estrutura normativa como a base neutra de toda relação intersubjetiva, desconsiderando a situação histórica de desigualdade a partir da qual o ordenamento jurídico foi estabelecido e da tábua de valores que ele determina como o padrão social a ser seguido.

Voltando à noção de direito subjetivo, a ciência do direito estabelece que toda pessoa que estiver situada sob a hipótese de uma posição jurídica (seja uma liberdade, pretensão, potestade ou imunidade: KELSEN, 2003, p. 140-145) tem direito a se beneficiar dela. Os direitos subjetivos não são exclusivamente relacionados ao direito de propriedade, mas este direito foi a base sobre a qual a teoria dos direitos subjetivos como posições jurídicas se desenvolveu ${ }^{4}$ e que ainda hoje exerce influência prática muito grande sobre essa teoria: direitos subjetivos são, a exemplo de seu direito originário, entendidos como posições exclusivas e excludentes, um direito que confere ao titular a exclusividade de seu benefício.

Essa exclusividade do direito subjetivo - proporcionada, na origem, pela característica erga omnes do direito de propriedade e pelo uso do silogismo jurídico em toda e qualquer disputa judicial, pelo qual a subsunção do fato à norma é o que determina se há ou não direito - tem sofrido, nas últimas décadas, uma grande relativização. Seja porque o direito de propriedade não é mais compreendido como absoluto, 
mas dependente do exercício de sua função social, ${ }^{5}$ seja porque, com o advento do constitucionalismo e da teoria dos direitos fundamentais, mais importante que a discussão sobre uma das partes ser titular ou não de um direito subjetivo, importa identificar se ela é titular de um direito fundamental, e em medida maior que o direito fundamental de que a contraparte seja titular.

Direitos fundamentais também se referem a posições jurídicas, porém não são caracterizados pela natureza absoluta e excludente dos direitos subjetivos. Eles visam à proteção de certos atributos de seu titular, em geral relacionados ao princípio da dignidade da pessoa humana, que só podem ser limitados pela incidência de outro direito fundamental.

Ora, se um valor ou interesse pode ser caracterizado como norma de caráter constitucional, ele não pode nem deve ser desconsiderado. Em termos jurídicos, todo interesse com essa característica possui dignidade, pois tem por base um direito fundamental e, portanto, deve ser protegido. Nesse sentido, numa colisão entre princípios ou entre direitos fundamentais de mesma dignidade constitucional, fica impensável imaginar a eliminação de um princípio em detrimento do outro, pois ambos os princípios devem permanecer, ainda que um prevaleça sobre o outro. Daí os rios de tinta que já se verteram para desenvolver as teorias sobre ponderação entre princípios - para que a prevalência de um princípio, quando em conflito com outro, não cause o esvaziamento deste - e sobre proporção ou proporcionalidade das decisões que, ao optarem por um dos princípios em conflito, devem aplicar a decisão da forma menos onerosa possível à parte derrotada.

Numa disputa que envolve direitos fundamentais contrapostos, importa, segundo a proeminente teoria dos direitos fundamentais de Robert Alexy, a ponderação entre eles, para que ambos sejam implementados na maior medida possível. Essa teoria, baseada em estudos dos julgados do Tribunal Federal Constitucional Alemão, tem sido base para a compreensão de conflitos entre direitos fundamentais em inúmeros países, seja pelos pesquisadores, seja pelos juízes dos tribunais constitucionais, seja pelos juízes de tribunais internacionais.

No Brasil não é diferente. A doutrina de Robert Alexy é referida em inúmeros acórdãos do Supremo Tribunal Federal e, com base nela, têm-se entendido o caráter principiológico das normas que conferem direitos fundamentais, o que impõe sua concretização na maior medida possível; ao contrário das normas que atribuem direitos subjetivos: as conhecidas regras do direito positivo que, segundo a teoria de Alexy, não admitem ponderação, devendo ser aplicadas de forma absoluta (como afirma Ronald Dworkin, numa condição de tudo ou nada).

Grosso modo, os direitos subjetivos, previstos em regras infraconstitucionais, que antes eram de aplicação absoluta, devem agora ser adjudicados se em conformidade com um direito fundamental, previsto em princípio constitucional, e na medida em que não restrinja outros princípios de maneira indevida. Vivemos a era da ponderação. ${ }^{6}$ Nesse 
sentido, a solução de um conflito real, no âmbito de um Estado de Direito, será solucionado a partir da conformação dos direitos fundamentais contrapostos em jogo, em cada caso concreto. A tábua de valores preestabelecida no ordenamento jurídico deixa de ser critério para estabelecer decisões quando o conflito entre partes envolver direitos fundamentais.

A ponderação entre direitos constitucionais sofre grande crítica dos teóricos morais, em especial por parte dos liberais, que compreendem a estrutura social como aquela formada por um contrato entre agentes morais kantianos. Segundo esta compreensão, a ponderação de direitos é algo inviável, seja porque direitos são absolutos (NOZICK, 1991), ou porque são trunfos (DWORKIN, 2001), ou porque possuem uma ordem predeterminada inalterável, com precedência da liberdade sobre a igualdade (RAWLS, 2000). Em artigo que iniciou acalorado debate sobre a ponderação de direitos em conhecido periódico internacional, Tsakyrakis (2009, p. 491) afirma que tratar de ponderação de direitos é o mesmo que parar de tratar da distinção entre o que é certo e errado para tratar do que é adequado e conveniente. Habermas (1997, p. 318) já havia apresentado sérias críticas, nesse mesmo sentido, à possibilidade de relativizar direitos ao se permitir prevalência a interesses ou valores que lhe sejam contrapostos (retira-lhes a força, ou a primazia estrita conferida a pontos de vista normativos). Além disso, e por causa disso, Habermas afirma que a ponderação, ao substituir os argumentos normativos pelos funcionalistas, gera o perigo de juízos irracionais.

De fato, a teoria dos direitos fundamentais possui a característica de atribuir igual validade a direitos individuais, direitos sociais, interesses públicos etc. (ALEXY, 2003, p. 131-132; 2009 p. 1-2), o que a torna uma teoria ímpar na compreensão do objeto da ciência jurídica. Talvez pela primeira vez na história uma estrutura teórica obtém certo êxito em traduzir, para o campo do direito, a organização social pluralista formada como o resultado de uma incessante luta por bens e posições (IHERING, 2010).

Nas teorias normativas tradicionais, baseadas em direitos subjetivos em vez de em direitos fundamentais, dá-se prevalência (quase) absoluta às liberdades públicas, também entendidas como direitos individuais, direitos de primeira dimensão ou direitos a abstenções. A compreensão do que é o Estado moderno e a do que são as relações sociais é tributária da visão de mundo captada pelos filósofos liberais, em especial por Locke, Rousseau e Kant. A liberdade abstrata do indivíduo foi declarada como direito humano autoevidente (HUNT, 2009), muito embora, na prática das relações sociais, tal direito era e tem sido aproveitado apenas pelas pessoas que integrassem o grupo econômico dominante.

Nem mesmo as lutas por igualdade (a segunda palavra de ordem do tríptico da revolução francesa), visando a melhores condições de trabalho, e que visavam à afirmação de direitos além da liberdade abstrata, causaram modificação nas teorias tradicionais de direito: as liberdades individuais permaneceram prevalentes em relação a quaisquer novos direitos que se afirmassem. Aliás, quando se apresentaram os direitos 
sociais como direitos de segunda geração ou dimensão, as demais teorias normativas

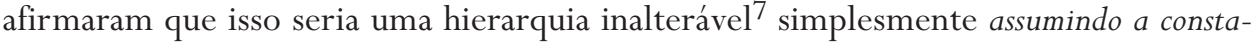
tação de que, na prática das relações sociais, eles já eram relegados à condição de direitos de segunda classe. Os direitos fundamentais de primeira dimensão permanecem sólidos por força de seu entendimento na forma de direitos subjetivos, enquanto os direitos de segunda dimensão, no entanto, por não serem compreendidos desse modo, são mantidos em segundo plano, sempre subordinados aos direitos subjetivos.

A teoria dos direitos fundamentais de Alexy, sem entrar na discussão sobre as concretas relações históricas que levaram as sociedades a afirmar certos direitos, reconhece que todo princípio normativo - identificado como direito fundamental ou preceito constitucional - representa um valor ou interesse socialmente relevante e que, justamente por sua relevância (pois alçado à condição de direito fundamental), deve ser de algum modo considerado e adjudicado. A teoria de Alexy, desse modo, permite a possibilidade de direitos sociais prevalecerem, ainda que de modo ponderado, sobre os antes absolutos direitos individuais.

Contudo, do fato de a teoria permitir que um direito social supere um direito individual não decorre necessariamente que, na vida real, os conflitos entre direitos individuais e direitos sociais sejam resolvidos em favor da prevalência destes últimos, ainda que de modo ponderado. Toda a estrutura social está montada, há séculos, sobre os pressupostos do liberalismo econômico. Assim, os direitos individuais, por serem considerados primordiais, são os que recebem mais proteção, justamente porque eles representam, no campo do direito, a estrutura econômica de dominação liberal inerente às sociedades ocidentais, e porque dão racionalidade a essa estrutura, permitindo o franco funcionamento do sistema capitalista. ${ }^{8}$

Holmes e Sunstein (1999) já demonstraram que todo direito demanda custo social para sua implementação, e que os custos para garantir os direitos individuais, embora elevadíssimos, não são percebidos porque estão embutidos no custo do aparato estatal (agências reguladoras de proteção aos mercados, serviços de polícia e Poder Judiciário para proteção da propriedade e dos contratos etc.). Ao mesmo tempo em que não sobram muitos recursos públicos para serem aplicados na garantia dos direitos sociais, isso retroalimenta o círculo vicioso da percepção pela qual direitos sociais não são tão importantes assim, ou que sua eficácia se encontra subordinada à proteção prévia dos direitos individuais.

O Supremo Tribunal Federal, que há muito nega a existência de direitos absolutos 9 e já compunha suas decisões a partir de ponderação de direitos, tem adotado o postulado da proporcionalidade nos termos da teoria de Robert Alexy ( $c f$., por exemplo, o voto do ministro Gilmar Mendes na Intervenção Federal 2.195-5/SP). Não obstante, mesmo nos votos proferidos pelos Ministros Gilmar Mendes e Eros Grau, a forma como a proporcionalidade é aplicada para fundamentar suas decisões difere do modelo proposto pela teoria; e os votos dos demais ministros que utilizam da ponderação 
para decidir em que medida um direito fundamental prevalece sobre o outro não costumam dar indicações de que o modelo alexyano foi seguido. ${ }^{10}$

Tal variedade de formas de se declarar a proporcionalidade de uma decisão indica que esse princípio, máxima ou postulado da teoria de Alexy é tão somente uma ferramenta doutrinária: ${ }^{11}$ embora importantíssima, não é uma estrutura necessária (no sentido lógico): a ponderação entre direitos, valores e interesses pode ser feita por outros meios e até por variações do modelo proposto. Exemplos históricos não faltam, como a razoabilidade desenvolvida pela prática jurisprudencial dos tribunais norte-americanos.

Porém, dado o sucesso da teoria de Alexy, toda ponderação acaba por fazer referência à proporcionalidade de sua teoria dos direitos fundamentais, com seus subtestes de adequação, necessidade e proporcionalidade em sentido estrito. A proporcionalidade da teoria de Alexy acaba se apresentando como o modelo a ser seguido em todas as práticas de resolução de conflitos entre direitos fundamentais. Todo modelo, toda representação de um objeto por algo diferente desse mesmo objeto é, por definição, fictício.

O problema não está tanto em apresentar a proporcionalidade em (sentido estrito) como a forma pela qual a ponderação se realiza, mas na impossibilidade de haver um critério racional pelo qual se justifique ou legitime a imposição de um sacrifício a uma das partes em benefício de outra pessoa ou do interesse público em geral. ${ }^{12}$ $\mathrm{Na}$ verdade, o princípio da proporcionalidade permite a escolha de um critério dentre uma gama de soluções corretas (SILVA, 2011, p. 293).

Silva afirma que, numa situação dessas em que a escolha pode se dar dentre várias opções igualmente válidas e legítimas, o critério deveria ser determinado pelo legislador (SILVA, 2011, p. 300). Porém, na vida real, a proporcionalidade se apresenta como uma ferramenta de utilidade principalmente para juízes e administradores, cada um com seu critério. Talvez seja essa incerteza que o levou a afirmar que ponderação exige percepção refinada, o que requer prática (SILVA, 2011, p. 274 e 301). Espero que a prática conduza à perfeição. Em especial nos conflitos que envolvem, de um lado, direitos individuais e, de outro, direitos sociais, em que o critério adotado, aparentemente na maioria das decisões públicas, tem dado prevalência àqueles em detrimento destes.

\section{O POSTULADO DA PROPORCIONALIDADE; PROBLEMAS NO ESTABELECIMENTO FICTÍCIO DO CRITÉRIO DE PONDERAÇÃO}

Toda teoria, por força de seu objeto e método, possui pontos fortes e imperfeições, compreendendo seu objeto de forma mais ou menos consistente em um ponto ou em outro. Com a teoria dos direitos fundamentais não é diferente. Sem embargo de suas inegáveis qualidades, ela também possui uma série de problemas, alguns decorrentes de sua (má) aplicação, outros inerentes à própria teoria.

Sobre os problemas que decorreriam de sua má aplicação, Möller (2012) redigiu uma densa defesa sobre a proporcionalidade da teoria de Alexy, em que afirma que as 
críticas sofridas foram realizadas não sobre a doutrina, mas sobre circunstâncias em que a doutrina foi mal aplicada. Não me estenderei sobre o tema da má aplicação da teoria, que não é objeto deste trabalho, mas o ponto da defesa de Möller parece residir na afirmação de que a teoria dos direitos fundamentais teria uma essência perfeita e que o problema estaria apenas na aplicação de interpretações pouco atrativas da teoria, como se houvesse uma única interpretação correta da teoria de Alexy, ou como se a teoria de Alexy permitisse encontrar a única interpretação correta de seu objeto, o direito.

Ora, nenhuma teoria social se mostra apta a ser aplicada em sua pureza, de modo que as críticas à aplicação devem, ao menos a meu ver, ser consideradas importante problema teórico. A teoria de Kelsen sofreu - e sofre - críticas por causa de sua pureza metodológica, mas Kelsen tinha por objeto conhecer o ser do direito. Alexy, ao buscar a função do direito, trata de finalidade e, consequentemente, da aplicação do direito. Não acatar os pontos relativos à impossibilidade de aplicação integral da teoria de Alexy a situações práticas é desprezar o único atributo que lhe legitima. De igual modo, afirmar que o problema está na falta de prática do aplicador - e não na impossibilidade real de sua aplicação conforme os cânones de Alexy - é o mesmo que afirmar que apenas os verdadeiramente preparados conseguirão resolver perfeitamente os problemas de aplicação da teoria.

Já sobre os problemas imanentes da teoria dos direitos fundamentais, pretendo tratar especificamente do seguinte: embora a teoria de Alexy estabeleça testes de adequação, necessidade e de proporcional em sentido estrito, e seja possível identificar níveis fraco, moderado ou forte de restrições aos direitos, de modo a minimizar a discricionariedade do julgador, não existe nenhum critério (ou valor de referência) a partir do qual dois direitos fundamentais possam ser objetivamente medidos, comparados ou sopesados. Nem quando os direitos fundamentais em conflito são direitos individuais, tampouco quando o conflito ocorre entre direito individual de um lado e, de outro, direito social.

$\mathrm{Na}$ verdade, presume-se que a proporcionalidade do método atribui racionalidade à escolha do critério de decisão. O julgador acaba, em cada caso concreto, criando um valor de referência - que não existe nem na realidade nem na estrutura ou na substância dos direitos em jogo - para realizar a comparação (e para decidir se a restrição é leve, moderada ou forte), o que mantém a proporcionalidade nos termos em que ela foi desenvolvida no âmbito do Tribunal Administrativo Prussiano na virada do século XX: como uma relação entre a eleição do critério de comparação e a decisão judicial (uma relação entre os elementos motivo e finalidade do ato administrativo objeto de controle judicial), mas não entre a decisão e os direitos em jogo. Ainda que um princípio prevaleça sobre outro, ou ainda que uma decisão seja considerada proporcional, o critério de ponderação/proporção se refere mais à própria decisão judicial que ao conflito em si.

Segundo as demais teorias normativas, que compreendem e estruturam o direito a partir de uma escala predeterminada de direitos subjetivos, a parte vencedora 
do conflito passa a ter o direito de ficar com o bem em disputa, pois o direito subjetivo da parte vencedora lhe confere essa posição jurídica. O direito da outra parte, ainda que identificado como direito subjetivo, permanece válido, mas totalmente ineficaz naquela situação concreta. Contudo, sempre há possibilidade de, em cada caso concreto, a decisão ser apenas parcialmente procedente, de modo a, de alguma forma, considerar algum aspecto fundamental do direito subjetivo da parte sucumbente. Para isso, não é preciso que a decisão se utilize de proporcionalidade. Outros postulados visando à acomodação dos direitos em jogos são possíveis, como a razoabilidade, a proibição do excesso, a equidade etc. Esses postulados, claramente utilizados como instrumentos de solução de controvérsia, são ferramentas postas à disposição pelas várias teorias normativas e que também pertencem mais ao discurso de quem decide o conflito do que aos direitos em conflito. Em regra, porém, um direito subjetivo prevalece, enquanto o outro sucumbe.

Segundo a teoria dos direitos fundamentais, no entanto, a parte vencedora também pode ficar com todo o bem objeto do conflito em disputa. Basta que, na decisão, a restrição do direito $A$ sobre o direito $B$ seja entendida como irrelevante e que a restrição do direito $B$ sobre o direito $A$ seja considerada forte. Esta definição quanto ao grau de restrição não é inerente a cada direito em jogo, mas depende do critério escolhido pela pessoa ou colegiado que decide o conflito. Algo que depende mais da visão de mundo de quem decide e do contexto histórico e social em que a decisão é aplicada.

Num eventual conflito entre direitos de mesma dimensão, por exemplo, entre dois direitos individuais, a importância social e histórica dada a eles permite, pela proporcionalidade, que ambos sejam considerados de alguma forma no momento da adjudicação. Num conflito entre a liberdade de imprensa de um jornal e a honra de uma pessoa objeto de uma reportagem, sempre é possível ponderar no sentido de permitir a publicação da matéria, desde que esta não lhe seja ofensiva.

No entanto, num conflito entre direitos de dimensões distintas, entre um direito individual e um social, ainda que a proporcionalidade se apresente como forma de solução desse conflito, ainda que a teoria de Robert Alexy identifique tais direitos como fundamentais de igual dignidade, o critério de solução, por ser externo à teoria de Alexy, tende a manter os direitos sociais subordinados aos direitos individuais, impedindo que aqueles possam ser protegidos efetivamente contra o grau de restrição que estes lhes causam.

Por exemplo, considere-se uma disputa entre direito individual de propriedade e direito social de moradia (ABREU, 2011). Pela teoria de Alexy, trata-se de direitos fundamentais de mesma dignidade constitucional e que poderiam ser mensurados e sopesados. Ao final, porém, o juiz de uma ação de desapropriação ou de usucapião precisaria decidir quem fica integralmente com o objeto da disputa judicial, não havendo possibilidade jurídica de distribuir o bem proporcionalmente entre as partes, na maior medida possível. Diferentemente das outras teorias normativas, em que o direito 
individual possui natureza de direito subjetivo e por este motivo subordina inteiramente o direito social, na teoria de Alexy, há espaço tanto para a vitória completa do direito individual quanto para a do direito social. Aqui, porém, qualquer que seja o resultado, o conflito não é resolvido por nocaute, mas por pontos. Afinal, a solução do conflito não se deve dar na base do tudo ou nada, mas de ponderação.

Enfim, a decisão, seja a proporcional (que adjudica direitos fundamentais), seja a fundamentada em outra teoria qualquer (que adjudica direitos subjetivos), serve para entregar o bem da vida à parte vencedora. A outra parte, sucumbente, fica sem o que queria na prática, porém confortada por saber que permanece com seu direito fundamental (afinal, ele sofre restrição na menor medida possível) para ser utilizado em outras oportunidades. Isso não é em nada diferente do que ocorre no âmbito das demais teorias normativas, em que a parte derrotada também permanece com todos os direitos que o ordenamento jurídico lhe atribui, embora fique sem o bem da vida litigado no caso concreto.

Nesse sentido, nas colisões entre direitos individuais e direitos sociais, constata-se que a proporcionalidade serve para justificar e legitimar as decisões tomadas nos processos judiciais e nos discursos governamentais, mas não se apresenta hábil a resolver os conflitos reais de modo a superar, por exemplo, o critério de custo e benefício que consequencialistas e utilitaristas utilizam para decidir, numa colisão de direitos, qual deve ser beneficiado e qual deve ser sacrificado. Tampouco supera as teorias deontológicas, que dão prevalência ao direito individual (direito subjetivo) por sua conformação a uma hierarquia de valores prevista na legislação.

De todo modo, para que uma decisão seja proporcional, é preciso que se estabeleça um critério que atue como valor de referência entre os direitos em colisão, para que seja possível compará-los e sopesá-los, e esse critério não é dado pela teoria. Para tornar a situação ainda mais problemática: se esse valor de referência é escolhido aleatoriamente ou com base em preferências do julgador, a decisão é arbitrária; se é escolhido com base em fato externo ao direito positivo, é antidemocrática. Isso é um problema na medida em que o postulado da proporcionalidade foi desenvolvido justamente para evitar ou mitigar a discricionariedade das decisões estatais! Como as decisões judiciais, por meio da proporcionalidade, tornam-se políticas (discricionárias, visando a conveniência e oportunidade da promoção de um direito em vez de outro, com base no critério estabelecido livremente pelo julgador), o princípio normativo prevalecente retira a eficácia das regras normativas vinculadas ao princípio derrotado. Numa estrutura normativa, isso substitui a segurança jurídica de uma tábua de valores predeterminada em lei por soluções individualizadas ao sabor dos valores e interesses mais apropriados segundo o critério escolhido pelo juiz.

Segundo os testes da proporcionalidade, a etapa da adequação trata de se saber se o exercício de um direito interfere no exercício de outro; a etapa da necessidade trata de se saber se haveria alguma forma menos onerosa de interferência e, concluída a 
análise do caso concreto nesta segunda fase, já se deve ter clara a existência de conflito entre direitos (ou interesses, ou valores constitucionais). Parte-se então para a terceira etapa, a da proporcionalidade em sentido estrito, em que haverá a escolha por um dos direitos, em que se "determina qual dos dois (ou mais) valores em questão terá prioridade nas circunstâncias concretas do caso” (MÖLLER, 2012, p. 715).

Para que a discricionariedade seja legitimada, e que a decisão sobre o conflito se apresente de fato proporcional, é preciso deixar a decisão e passar a discutir a racionalidade do critério pelo qual a decisão deve ser feita. O teste da proporcionalidade em sentido estrito é o momento em que se deixa de resolver o problema real para se resolver um jogo de eleição de critérios que, de algum modo, será utilizado para fundamentar a solução do conflito. Tsakyrakis (2009, p. 474) é cético quanto à proporcionalidade, pois, segundo ele, as razões morais que verdadeiramente decidem o conflito de direitos ficam ocultas. Möller (2012, p. 717) afirma que a argumentação moral que estabelece o critério deve ser discutida no momento da proporcionalidade em sentido estrito, e que esta ferramenta auxilia na apresentação de razões aceitáveis de ponderação.

Isso evidencia que, no âmbito da teoria dos direitos fundamentais de Alexy, o conflito de direitos é decidido por alguma coisa externa à proporcionalidade, e que esta serve para justificar a tomada de decisão por absolutamente qualquer critério. Nessa situação, Tsakyrakis acerta ao identificar que o critério foi criado apenas para justificar uma decisão que já foi tomada antes mesmo de se fazer qualquer ponderação entre os direitos em conflito, mostrando que a proporcionalidade em sentido estrito não auxiliou a resolução do conflito, mas encobriu as razões que levaram o juiz a decidir. A proporcionalidade, neste sentido, está mais para um argumento de autoridade (ATIENZA, 2012; COPI, 1978) que para um argumento racional.

A questão sobre a mensuração de direitos, valores e interesses e sua consequente ponderação não reside, a meu ver, na incomensurabilidade teórica ${ }^{13}$ entre eles (já que o conflito real entre eles determina a necessidade de escolha entre um e outro com base em algum critério), mas justamente na forma de se escolher esse critério. Se não há critério para fundamento da decisão, surge a questão da fundamentação do critério: seria preciso aplicar os testes de adequação, necessidade e ponderação para fundamentar a escolha do critério? Em caso positivo, isso levaria a uma regressão por novas demandas no sentido de se decidir sobre as bases dessa decisão, regressão esta que não terminaria nunca (regressus in infinitum). Nesse sentido, parece-me que o fundamento teórico que legitima a proporcionalidade é tão ficcional quanto, por exemplo, a norma fundamental da teoria pura do direito (KELSEN, 1986, p. 328-329). ${ }^{14}$

As ficções são criadas exclusivamente como critérios visando à solução de problemas práticos em sociedade. Ao se aceitar os estatutos da teoria dos direitos fundamentais e seu exitoso método de ponderação de direitos, ele passa a ser a forma oficial de resolução de conflitos em sociedade, o parâmetro pelo qual todos os problemas devem ser resolvidos. 
A proporcionalidade foi criada como um meio fictício para a resolução de conflitos, e somente se justifica na medida em que atinge essa finalidade. $O$ parâmetro para decidir proporcionalmente, porém, não é dado pela teoria dos direitos fundamentais. Na verdade, esse parâmetro não é dado por teoria jurídica alguma, mas pelas bases de uma certa visão de mundo que o juiz considera válida ou legítima para ponderar os direitos em jogo. ${ }^{15}$ Não obstante, e com base em Vaihinger (1952), deve-se ficar claro que qualquer visão de mundo é ficcional, pois baseada em certos interesses, valores e vontades - na forma de compreender o mundo, e não no próprio mundo -, que se impõe não só frente ao pensamento e à realidade objetiva, mas também frente aos interesses das demais pessoas e dos grupos sociais.

\section{CONSIDERAÇÕES FINAIS}

Os conflitos reais, caso não houvesse Estado, seriam resolvidos, em última instância, na base da força física das partes em disputa. Com o Estado, são decididos com base em normas jurídicas (e nos valores sociais que dão conteúdo e sentido a elas). Porém o que se deve frisar é que as normas, embora formalmente iguais, não possuem essa mesma igualdade em termos materiais. ${ }^{16} \mathrm{O}$ que significa dizer que alguns valores e algumas normas são historicamente mais fortes que outros. Por exemplo, é muito difícil encontrar decisões judiciais que deem prevalência ao direito de moradia quando em colisão com o direito de propriedade, e ambos os direitos são direitos fundamentais igualmente constitucionalizados.

Se os direitos fundamentais são dotados de igual validade, sendo formalmente iguais, o que confere prevalência de um sobre o outro em qualquer situação concreta, o que dá a cada direito força normativa maior ou menor em relação aos demais direitos não está dentro do direito, mas fora dele. ${ }^{17} \mathrm{~A}$ eficácia normativa é um dado da realidade social e não da realidade jurídica. Embora o direito e a ciência do direito se apresentem de modo objetivo e impessoal, como se todos os direitos fossem igualmente relevantes, ${ }^{18}$ o resultado prático acaba dependendo de se saber qual dos direitos em colisão se relaciona em maior medida com o padrão normativo da sociedade. ${ }^{19}$ A força da norma jurídica depende mais de seu conteúdo (adequação a valores e interesses sociais que estruturam a sociedade) que de sua forma (adequação ao sistema jurídico).

Ao se permitir ao julgador que estabeleça o critério de ponderação, ele tende a escolher um valor ou interesse que lhe seja relevante dentro de seu ponto de vista, o que é altamente discricionário, para dizer o mínimo. Ainda que o juiz justifique o critério com base numa consciência jurídica universal ou na prática judicial, ${ }^{20}$ ou que o fundamente em algum argumento de ordem moral, esse dever de fundamentação não é exigência exclusiva da teoria dos direitos fundamentais; ao contrário, neste aspecto (dever de fundamentação), ela em nada se distingue das demais teorias de adjudicação. 
Se tanto no âmbito da teoria dos direitos fundamentais quanto no das demais teorias, não há elementos para identificação do critério a se decidir, então Kelsen permanece atual, dada sua afirmação de que é possível decidir de qualquer jeito, até mesmo de forma contrária à lei. ${ }^{21}$ Assim, se há interesse pela solução do conflito em favor do direito $A$ em contraposição ao direito $B$, basta escolher um critério que beneficie o direito $A$ para a decisão que lhe favorece parecer proporcional e parecer que houve uma ponderação racional entre os direitos em colisão.

Este, aliás, é o núcleo da crítica feita por Enrique Haba aos métodos de resolução de conflitos apresentados pela generalidade das teorias jurídicas. Com apoio na doutrina do realista norte-americano Jerome Frank, Haba afirma a existência de um mito jurídico básico, a crença de que um jurista bem preparado pode encontrar o direito (a solução de um conflito) simplesmente a partir de sua ação diligente na aplicação de uma teoria esteticamente satisfatória, sistematizadora do direito de modo harmonioso, consistente e uniforme; aí então o direito (ou a solução) "brotará quando agitarmos a varinha mágica de um princípio racionalizador” (apud HABA, 2004, p. 60). Segundo Haba, a função pragmática desse mito é camuflar tanto as indeterminações próprias da linguagem jurídica quanto as responsabilidades pessoais dos juristas. O princípio racionalizador, sempre dado como pressuposto, nunca porém provado, não passa de um recurso retórico por excelência (HABA, 2001). ${ }^{22}$

O que promove a relação entre a decisão e os direitos a ponderar não é, portanto, a proporcionalidade, mas o critério pelo qual a proporcionalidade (em sentido estrito) seria aplicada. É preciso, seja na teoria dos direitos fundamentais, seja em qualquer outra, que os valores e interesses subjacentes ${ }^{23}$ sejam evidenciados, de forma a mostrar a identificação do critério com um certo estado de coisas. Aliás, a referência expressa ao estado de coisas sobre o qual os conflitos sociais (e, por consequência, os jurídicos) no estabelecimento de critérios de decisão é a solução sugerida por Haba para evitar o mito jurídico básico. Segundo este autor, a interpretação jurídica se refere à prática de realizar um ou outro valor, e ela só pode ser apreciada com alguma nitidez se as características dos valores invocados forem precisamente identificadas e abertamente declarados. ${ }^{24}$ Ao se "abrir o jogo" (HABA, 2002, p. 528) para identificar quais os valores que subjazem à escolha do critério, torna-se possível o controle público da racionalidade do critério adotado.

Qual a vantagem, então, da teoria dos direitos fundamentais sobre as demais teorias jurídicas? A meu ver, não é a proporcionalidade, que absolutamente não resolve a questão da eleição do critério da decisão de forma melhor, mais abrangente ou mais profunda que outras teorias. Ela é incapaz, por si só, de justificar a escolha de um critério em detrimento de outro, algo que, qualquer que seja a teoria, deve ser realizado com base na realidade mesma, e não no estreito âmbito da teoria ou do sistema normativo. Nesse sentido, a proporcionalidade se apresenta como a forma estabelecida por Alexy para solução de conflitos no âmbito da teoria dos direitos fundamentais, 
porém sem qualquer possibilidade de, por si só, proporcionar a criação de um critério racionalmente justificado para promover sua aplicação.

Isso, contudo, não é motivo para sugerir que a teoria dos direitos fundamentais seja descartada. Ela se trata, como afirmado na Introdução, da primeira estrutura teórica que confere importância a direitos sociais e a interesses públicos, desde que positivados na Constituição, no mesmo patamar dos chamados direitos individuais, próprios de uma estrutura social que serve à manutenção de condições sociais de desigualdade. Não quero com isso afirmar que a teoria dos direitos fundamentais seja a única forma de dar força constitucional a direitos sociais e que ela permitirá que se faça isso na prática das decisões judiciais, mas que essa característica inerente se apresenta altamente conformada à estrutura social pluralista de nossos dias, permitindo que os mais diversos grupos sociais tenham condições de lutar por certos valores e interesses e vê-los prevalecer. Não há problema algum em se tratar a proporcionalidade como ficção. O problema está em não considerá-la neste aspecto importante de sua natureza.

NOTAS

1 A pesquisa de acórdãos arquivados no banco de dados do STF encontrou centenas de decisões colegiadas a partir de buscas com as palavras-chave direitos fundamentais (250 acórdãos), direitos humanos (328), direitos sociais (75), políticas públicas (88), ponderação (214), proibição de(o) excesso (22) e proporcionalidade (644). Em muitos desses acórdãos, houve prevalência de direito individual sobre atos legislativos (em especial nas decisões de habeas corpus). Já em outros vários, houve a supremacia de um interesse público sobre o direito individual (por exemplo, na Intervenção Federal 2.195-5/SP), o que dá claras indicações de que o STF não decide sempre em favor de direitos individuais, reconhecendo que as situações concretas da vida determinam a necessidade de comparar e ponderar direitos, interesses e valores para que seja possível decidir conflitos. Análises mais aprofundadas estão sendo realizadas para apresentar esses dados com precisão. De todo modo, já foi possível identificar que em nenhum dos acórdãos constante dessa base de dados há uma discussão que envolve claramente duas partes em que uma seja titular de um direito individual e outra, um direito social. Isso determinou a alteração do plano de pesquisa bienal para ampliar a busca por ações judiciais nos tribunais brasileiros e identificar se há demandas nesse sentido. Intenta-se analisar os votos dos ministros do STF em todos os acórdãos de processos em que haja colisão entre direitos fundamentais e identificar se houve utilização da proporcionalidade para solucionar o conflito em julgamento. O estudo dos acórdãos está se pautando pela elaboração de um relatório com os seguintes pontos: (1) Qual é o número do acórdão? (2) Trata-se de acórdão do Plenário ou de uma turma? (3) Quem é o relator? (4) Quem é o revisor? (5) Quais são os direitos fundamentais em colisão (direito individual / direito social/ valor /interesse)? (6) A proteção dada a um interfere ou impede a proteção dada a outro? De que modo? (7) Qual o fundamento dos votos de cada ministro (ponderação / razoabilidade / proporcionalidade / outro?) (8) Como esse fundamento foi utilizado para resolver o conflito? (9) O fundamento adotado por um ministro foi adotado pelos demais para a apresentação de seu voto? Foi adotado integralmente ou houve adaptações? (10) Qual foi o direito fundamental que prevaleceu? (11) Em que medida 
esse direito prevaleceu sobre o outro? (12) Há base jurisprudencial ou doutrinária apresentada no próprio voto para fundamentar o critério utilizado? Em caso positivo, qual?

2 Isso que afirmamos não é novidade. No âmbito do Estado de Direito, a resolução de conflito com emprego de força física pelas partes é ilícito, pois o monopólio da força física é atribuído ao Estado como um de seus elementos essenciais. Daí a impossibilidade jurídica de qualquer uma das partes, em regra, usar de sua condição física (ou econômica, ou social, ou política) superior para manter um bem ou posição - ou tomá-lo da outra parte. Eis porque o Estado-juiz transforma o conflito em uma discussão: pois as partes, dentro do Estado, só podem argumentar a legitimidade de sua situação a partir de valores sociais vigentes e justificá-la a partir de normas jurídicas positivadas.

3 É o Estado que deve decidir todo e qualquer conflito que envolva seus cidadãos. Como a todos os cidadãos é conferida, formalmente, igual dignidade e consideração, a disputa judicial é entendida como uma disputa entre iguais, que somente teriam de diferente as razões pelas quais estão em conflito. Esta é a forma jurídica de resolver um conflito material que, na realidade, não é feito de partes iguais, tampouco ocorre em igualdade de condições. A este respeito, $c f$. Mastrodi (2012, p. 161-165).

4 “O direito subjetivo em sua origem é o âmbito de soberania que cada um possui sobre si mesmo e sobre seus bens, ou seja, um direito de propriedade.” (HIERRO, 2000, p. 351-375)

5 Cf. Brasil, STF, ADI 2.213 MC/DF, Rel. Min. Celso de Mello, j. 04/04/2002, Tribunal Pleno, publ. DJ 23/04/2004. Há excerto da ementa deste julgado que merece transcrição: “O direito de propriedade não se reveste de caráter absoluto, eis que, sobre ele, pesa grave hipoteca social, a significar que, descumprida a função social que lhe é inerente (CF, art. $\left.5^{\circ}, \mathrm{XXIII}\right)$, legitimar-se-á a intervenção estatal na esfera dominial privada, observados, contudo, para esse efeito, os limites, as formas e os procedimentos fixados na própria Constituição da República. - O acesso à terra, a solução dos conflitos sociais, o aproveitamento racional e adequado do imóvel rural, a utilização apropriada dos recursos naturais disponíveis e a preservação do meio ambiente constituem elementos de realização da função social da propriedade. A desapropriação, nesse contexto - enquanto sanção constitucional imponível ao descumprimento da função social da propriedade - reflete importante instrumento destinado a dar consequência aos compromissos assumidos pelo Estado na ordem econômica e social. - Incumbe, ao proprietário da terra, o dever jurídico-social de cultivá-la e de explorá-la adequadamente, sob pena de incidir nas disposições constitucionais e legais que sancionam os senhores de imóveis ociosos, não cultivados e/ou improdutivos, pois só se tem por atendida a função social que condiciona o exercício do direito de propriedade, quando o titular do domínio cumprir a obrigação (1) de favorecer o bem-estar dos que na terra labutam; (2) de manter níveis satisfatórios de produtividade; (3) de assegurar a conservação dos recursos naturais; e (4) de observar as disposições legais que regulam as justas relações de trabalho entre os que possuem o domínio e aqueles que cultivam a propriedade.” Cf., ainda, Oliveira e Lacerda (2011).

6 Frase atribuída a T. Alexander Aleinkoff e utilizada por Tsakyrakis (2009, p. 468). Também já se utilizou a frase era da proporcionalidade em Contiades e Fotiadou (2012, p. 660).

7 Cf., por exemplo, a ordem lexicográfica dos princípios de justiça de Rawls (2000, p. 333).

8 Nesse sistema, sua racionalidade impõe que haja acumulação de capital, e não sua distribuição, daí o descaso com direitos sociais, relacionados à promoção de políticas públicas e ao uso de recursos escassos em atividades alheias à produção econômica; daí a proteção máxima à propriedade (em especial, dos meios de produção), à liberdade de iniciativa (aos que possuem bens de produção, para produzir) e à liberdade de contratar (aos que não possuem bens de produção, para procurar emprego).

9 O STF também já tem reconhecido direitos sociais como direitos fundamentais e, nesse sentido, passíveis de serem postos em ponderação quando em colisão com direitos individuais. As demandas que envolvem direitos sociais têm chegado ao STF na forma de recursos extraordinários sobre políticas públicas, em que o Estado é instado a promover judicialmente algum direito social, ou em sede de controle concentrado, em que não há propriamente um conflito entre partes. Aliás, foram aqui as mais expressivas afirmações do STF quanto à importância e à fundamentalidade dos direitos sociais (em especial, a ADI 1.458-7 de 1996 e a ADPF 45/2004, ambas relatadas pelo ministro Celso de Mello). A respeito desta pesquisa em andamento, $c f$. nota 1 , acima.

10 Pesquisa ainda em andamento, $c f$. nota 1, acima. De todo modo, saliente-se que o próprio Alexy não possui uma fórmula "verdadeira" sobre a "única aplicação correta" de sua teoria. Afinal, valores, interesses, princípios e direitos fundamentais não são matematicamente auferíveis. 
11 “Doctrinal tool.” Cf. Möller (2012, p. 709, 710 e 726).

12 "Ponderação é algo sobre o sacrifício que se pode legitimamente demandar de uma pessoa em benefício de outra ou do público.” (MÖLLER, 2012, p. 716)

13 Crítica apresentada por Tsakyrakis (2009) à teoria de Alexy e rebatida, a meu ver, com êxito, por Möller (2012) e Silva (2011).

14 Sobre o estatuto teórico da ficção em geral e da ficção jurídica em particular, cf. Vaihinger (1952).

15 Essas considerações são claras, no campo da interpretação jurídica, para autores como Ross: "O juiz é um ser humano. Por trás da decisão tomada encontra-se toda sua personalidade. Mesmo quando a obediência ao direito (a consciência jurídica formal) esteja profundamente enraizada na mente do juiz como postura moral e profissional, ver nesta o único fator ou móvel é aceitar uma ficção. O juiz não é um autômato que de forma mecânica transforma regras e fatos em decisões. É um ser humano que presta cuidadosa atenção em sua tarefa social, tomando decisões que sente ser corretas de acordo com o espírito da tradição jurídica e cultural.” (2000, p. 169). “[...] é impossível para o próprio juiz, bem como para os demais, distinguir entre as valorações atribuídas ao legislador [...] Do mesmo modo, toda interpretação jurídica em sentido próprio inclui presunções que tangem aos critérios e valores sociais que motivaram o legislador. Se o juiz, errônea ou acertadamente, identifica suas próprias valorações com as do legislador, os dois tipos de interpretação se fundem em seu espírito." (2000, p. 170) "É imperioso que afirmemos claramente que a interpretação não tem ponto de partida linguístico independente, mas que desde o início é determinada por considerações pragmáticas sob a forma de senso comum." (2000, p. 175).

16 Isso foi tratado em Mastrodi (2012, p. 165): "Reconhecemos a natureza principiológica das normas definidoras de direitos fundamentais e concordamos com a solução teórica, desenvolvida em especial por Dworkin e Alexy, para a ponderação e aplicação de princípios colidentes. Parece-nos, contudo, existir um limite intransponível para essa teoria: ao definir os direitos fundamentais como normas principiológicas, ao lhes conferir igual dignidade normativa (e em geral, igual dignidade constitucional), entende-se que um direito qualquer, tornado eficaz nos dias de hoje (em detrimento de outro), pode ter sua sorte mudada em dias futuros, dando-se prevalência a outro direito, anteriormente ineficaz (por conta da prevalência do primeiro). Os princípios são entendidos sempre caso a caso, nunca de modo amplo.

Na prática, porém, parece que é o atual estado de forças sociais que impõe a eficácia de um direito fundamental em detrimento da eficácia de outro. Certos valores, que expressam certos interesses, delimitados pela existência de certas necessidades, são impostos em maior ou menor medida pelos fatores reais de poder de Lassalle. Ou seja, embora a lógica permita que um direito seja eficaz hoje, mas amanhã não, a prática demonstra que os direitos eficazes são sempre os conformados à estrutura social."

17 Validade é qualidade da norma que pertence formalmente ao sistema normativo. Em termos semióticos, trata-se da relação sintática dos elementos do sistema entre si e em relação ao próprio sistema. Eficácia (no sentido de efetividade) tem a ver com o sentido (semântica) que as normas possuem na relação delas com o mundo real, sentido este que não é obtido a partir da sintaxe, e que não é criado per se, mas que se constrói pragmaticamente na relação entre mundo jurídico e mundo real (que abarca o mundo jurídico).

18 Importa reafirmar que, em termos sintáticos, sim, todos os direitos e todas as normas jurídicas possuem igual validade, mesma dignidade dentro do sistema normativo (KELSEN, 2003, p. 387-397). O sentido dos direitos e das normas, porém, não é dado pelo sistema, mas obtidos a partir da relação desse sistema normativo com a realidade social.

19 Cf. item 1 deste trabalho e, em termos similares, Mastrodi (2012).

20 Que são as bases das duas vertentes mais conhecidas do positivismo realista, a psicológica e a comportamentista (ROSS, 2000, p. 97-100).

21 Ou "produzir uma norma que se situe completamente fora da moldura que a norma a aplicar representa" (KELSEN, 2003, p. 394).

22 Em seguida, o mesmo autor afirma: "Com efeito, dita crença dá conta de algo que, seja como for, é certo que se apresenta assim. Tal presença não só é efeito de certas causas reais, por um lado, como também causam, por outro lado, efeitos subsequentes na própria realidade, pois os que atuam de tal ou qual maneira porque vê assim (crê nisso). Aqui vem 
à baila... o teorema de Thomas: 'Se os homens definem [i.e. imaginam] as situações como reais, estas são reais em suas consequências'” (HABA, 2001, p. 192).

23 “O direito está inteiramente a serviço de valores." (HABA, 2002, p. 522)

24 “O jurista realista precisa saber, de forma bem determinada, a que grupos de pessoas e em que 'coisas' deve beneficiar concretamente ao se pôr um valor em prática; como também quais grupos e em que estes serão prejudicados por isso, e quem não seria tocado nem para o bem nem para o mal pela decisão proposta.... Essa discussão não é linguística, tampouco de natureza basicamente valorativo-optativa. Constitui uma questão de fatos. Para abordá-la, é indispensável examinar a realidade social.” (HABA, 2002, p. 522)

\section{REFERÊNCIAS BIBLIOGRÁFICAS}

ABREU, João Maurício Martins de. A moradia informal no banco dos réus: discurso normativo e prática judicial. Revista Direito GV, v.7, n.2, 2011, p. 391-416. . On constitutional rights to protection. Legisprudence, v. 3, n. 1, jul. 2009, p. 1-17. On balancing and subsumption. A structural comparison. Ratio Juris, v. 16, n. 4, dez. 2003, p. 433-449. . Constitutional rights, balancing, and rationality. Ratio Juris, v. 16, n. 2, jun. 2003, p. 131-140.

Press, 2002. . A Theory of Constitutional Rights. Trad. para o inglês de Julian Rivers. Oxford: Oxford University Teoría de los derechos fundamentales. Trad. Manuel Atienza e Isabel Espejo. Madri: Centro de Estudios Constitucionales, 2001.

ALVES, Alaôr Caffé. As raízes sociais da filosofia do direito: uma visão crítica. In: ALVES, Alaôr Caffé et al. $O$ que é a filosofia do direito? Barueri: Manole, 2004.

ATIENZA, Manuel. O argumento de autoridade no direito. Trad. André Rufino do Vale. Revista Novos Estudos Jurídicos, v. 17, n. 2, 2012, p. 144-160.

COHEN-ELIYA, Moshe. PORAT, Iddo. American Balancing and German Proportionality: the historical origins. Int J Constitutional Law, v. 8, n. 2, 2010, p. 263-286.

CONTIADES, Xenophon; FOTIADOU, Alkmene. Social rights in the age of proportionality: Global economic crisis and constitutional litigation. Int J Constitutional Law, v. 10, n. 3, 2012, p. 660-686.

COPI, Irving M. Introdução à lógica. Trad. Álvaro Cabral. 2. ed. São Paulo: Mestre Jou, 1978.

DWORKIN, Ronald. Taking rights seriously. 18. ed. Cambridge: Harvard University Press, 2001.

HABA, Enrique P. Precomprensiones, racionalidad y métodos en las resoluciones judiciales. Doxa: Cuadernos de Filosofía del Derecho, n. 22, 2004, p. 48-78.

. Metodología realista-crítica y ética del razonamiento judicial: (Realismo jurídico como alternativa práctica al discurso normativista de los jueces). Doxa: Cuadernos de Filosofía del Derecho, n. 25, 2002, p. 503-531.

. Rehabilitación del no-saber en la actual teoría del derecho: el 'bluff' Dworkin. Doxa: Cuadernos de

Filosofía del Derecho, n. 24, 2001, p. 165-201.

HABERMAS, Jürgen. Direito e democracia: entre facticidade e validade. Trad. Flavio B. Siebeneichler. Rio de Janeiro: Tempo Brasileiro, 1997.

HIERRO, Liborio. ¿Qué derechos tenemos? Doxa: Cuadernos de Filosofía del Derecho, n. 23, 2000, p. 351-375. HOLMES, Stephen; SUNSTEIN, Cass. The cost of rights: why liberty depends on taxes. New York: Norton, 1999. HUNT, Lynn. A invenção dos direitos humanos: uma história. Trad. Rosaura Eichemberg. São Paulo: Cia. das Letras, 2009.

IHERING, Rudolf von. A luta pelo direito. Trad. Agnes Cretella e José Cretella Júnior. 6. ed. São Paulo: Revista dos Tribunais, 2010.

KELSEN, Hans. Teoria geral das normas. Trad. José Florentino Duarte. Porto Alegre: Sergio Antonio Fabris Editor, 1986.

Teoria pura do direito. Trad. João Baptista Machado. São Paulo: Martins Fontes, 2003.

KLATT, Matthias; EISTER, Moritz. Proportionality: a benefit to human rights? Remarks on the I CON controversy. Int J Constitutional Law, v. 10, n. 3, 2012, p. 687-708. 
KUMM, Mathias. Constitutional rights as principles: on the structure and domain of constitutional justice. A review essay on A Theory of Constitutional Rights, by Robert Alexy. Int J Constitutional Law, v. 2, n. 3, 2004, p. 574-596.

MASTRODI, Josué. Sobre o real fundamento dos direitos fundamentais. Revista Digital de Direito Público, v. 1, n. 1, 2012, p. 150-187.

Levando o conceito de autopoiese a sério: por que o direito não pode ser compreendido a partir do paradigma de Niklas Luhmann. Revista da Faculdade de Direito Cândido Mendes, ano 16, n. 16, 2011, p. 155-173. MÖLLER, Kai. Proportionality: Challenging the critics. Int J Constitutional Law, v. 10, n. 3, 2012, p. 709-731.

p. 453-468. Balancing and the structure of constitutional rights. Int J Constitutional Law, v. 5, n. 3, 2007,

NOZICK, Robert. Anarquia, Estado e utopia. Trad. Ruy Jungmann. Rio de Janeiro: Jorge Zahar, 1991.

OLIVEIRA, Álvaro Borges de; LACERDA, Emanuela Cristina Andrade. Evolução constitucional da propriedade. Estudios constitucionales, Santiago, v. 9, n. 2, 2011. Disponível em:

$<$ http: / / www.scielo.cl/scielo.php?script=sci_arttext\&pid $=S 0718-52002011000200018 \& \operatorname{lng}=e s \& n r m=i s o>$. Acesso em: 11 mar. 2013.

RAWLS, John. Uma teoria da justiça. Trad. Almiro Pisetta e Lenita Esteves. São Paulo: Martins Fontes, 2000. ROSS, Alf. Direito e justiça. Trad. Edson Bini. Bauru: Edipro, 2000.

SILVA, Virgilio Afonso da. Comparing the incommensurable: constitutional principles, balancing and rational decision. Oxford Journal of Legal Studies, v. 31, n. 2, 2011, p. 273-301.

TSAKYRAKIS, Stavros. Proportionality: An assault to human rights? Int J Constitutional Law, v. 7, n. 3, 2009, p. 468-493.

VAIHINGER, Hans. The philosophy of 'as if'. Londres: Routledge, 1952.

Josué Mastrodi 
